\title{
RANCANG BANGUN \\ PENGUATAN UMKM BERBASIS KULINER \\ KHAS DAERAH MENUJU CIREBON HALAL \\ TOURISM
}

\author{
Agus Hasanuddin \\ STEI AL ISHLAH CIREBON \\ ade.hasan09@gmail.com
}

\section{Abstrak}

Rancang bangun penguatan UMUKM berbasis kuliner khas daerah menuju Cirebon Halal Tourism. Penelitian ini bertujuan untuk mengidentifikasi dan menyusun strategi penguatan UMKM berbasis kuliner khas Cirebon dalam mengembangkan Halal tourism sertamenyusun model penguatan UMKM berbasis kuliner khas Cirebon dalam mengembangkan Halal tourism. Data yang digunakan dalam penelitian ini adalah yang diperoleh secara langsung melalui Focus Group Discussion (FGD) dan wawancara dari para narasumber yang terlibat dalam penelitian, yaitu dinas UMKM Kabupaten dan Kota Cirebon, dinas pariwisata Kabupaten dan Kota Cirebon, Perhimpunan UMKM Kabupaten dan Kota Cirebon, serta perwakilan UMKM Kabupaten dan Kota Cirebon. Hasil SWOT dari penilaian responden terhadap faktor internal didapatkan total skor rata-rata IFE sebesar 1.929. Hal ini mengindikasikan bahwa posisi strategi internal UMKM kuliner khas daerah Cirebon berada pada kondisi lemahsedangkanhasil dari penilaian responden terhadap faktor eksternal UMKM kuliner khas Cirebon didapatkan total skor rata-rata EFE sebesar 3.149. Hal ini mengindikasikan bahwa posisi external pada kondisi banyak peluang. Analisis matriks IE dengan hasil skor dari Matriks IFE sebesar 1,929 dan skor Matriks EFE sebesar 3,149, sehingga apabila masing-masing skor dipetakan kedalam Matriks IE maka posisi UMKM kuliner khas daerah Cirebon berada pada kuadran III. memiliki makna bahwa posisi ini menandakan sebuah organisasi yang lemah namun sangat 
berpeluang.Rekomendasi strategi yang diberikan adalah Ubah Strategi, artinya organisasi disarankan untuk mengubah strategi sebelumnya.Sebab, strategi yang lama dikhawatirkan sulit untuk dapat menangkap peluang yang ada sekaligus memperbaiki kinerja organisasi.

\section{BAB I \\ PENDAHULUAN}

\subsection{Latar Belakang}

Halal tourism adalah salah satu sistem pariwisata yang diperuntukan bagi wisatawan, baik untuk wisatawan Muslim maupun non-Muslim yang pelaksanaannya mematuhi aturan syariah (El Hasan, 2014).Pada perkembangannya, setiap negara dan/atau daerah menjadikan Halal tourism sebagai ikon utama wisata untuk menarik wisatawan. Menurut data statistik Kementerian Pariwisata RI, kunjungan wisatawan mancanegara (wisman) ke Indonesia pada tahun 2016 mencapai $11,973,122.00$ wisman. Dari jumlah tersebut sebanyak 1,2 juta wisman atau sekitar 18 persen merupakan wisatawan Muslim ${ }^{1}$. Salah satu tujuan wisata di Indonesia yang cukup menarik di kunjungi adalah Provinsi Jawa Barat. Menurut data yang diperoleh dari Pusat Data dan Informasi Kementerian Pariwisata dan Ekonomi Kreatif dan Badan Pusat Statistik (BPS), setiap tahunnya Jawa Barat dikunjungi tidak kurang dari 700ribu wisman atau pertumbuhannya dapat mencapai $25 \%$ per tahunnya.

Salah satu tujuan Halal Tourism di Jawa Barat adalah Cirebon. Cirebon yang dikenal sebaga Kota Wali menyimpan sejuta pesona yang wajib dikunjungi Secara geografis, Cirebon memiliki keunggulan dibandingkan daerah lainnya di Jawa Barat. Kemudahan akses transportasi dari adanya modal transportasi darat (Tol Cikampek - Palimanan, Pintu gerbang ke Jawa Tengah, jalan nasional Pantai Utara Jawa), transportasi laut (Pelabuhan Cirebon) dan transportasi udara (Bandara Cakrabuana dan dekat dengan Bandara Internasional Jawa Barat - Kertajati), menjadikan Cirebon sebagai wilayah dengan seribu pintu masuk.

Dari berbagai potensi wisata yang ada di Cirebon terdapat permasalahan yaitu belum adanya produk yang mengemas Halal tourism

${ }^{1}$ http://www.kemenpar.go.id/asp/ringkasan.asp?c=110. Data Kunjungan Wisatawan Mancanegara Bulanan Tahun 2016.[07 Juli 2017]. 
secara utuh.Salah satu yang diburu dan dicari oleh wisatawan ketika berkunjung ke Cirebon adalah kuliner khas daerahnya. Sampai saat ini belum ada keseriusan pemerintah daerah dalam mengintegrasikan Halal torism dengan kuliner khas daerah. Pemerintah belum secara serius mengelola kuliner khas daerah untuk menjadi salah satu daya tarik Halal Tourism.

Berdasarkan permasalahan diatas, diperlukan solusi dan strategi menghadapi kompetisi dalam Halal tourism melalui penelitian tentang Rancang Bangun Penguatan UMKM Berbasis Kuliner Khas Daerah Menuju Cirebon Halal Tourism.

\subsection{Rumusan Masalah}

1. Bagaimana strategi penguatan UMKM berbasis kuliner khas Cirebon dalam mengembangkan Halal tourism?

2. Bagaiamana model penguatan UMKM berbasis kuliner khas Cirebon dalam mengembangkan Halal tourism?

\subsection{Tujuan Penelitian}

1. Mengidentifikasi dan menyusun strategi penguatan UMKM berbasis kuliner khas Cirebon dalam mengembangkan Halal tourism

2. Menyusun model penguatan UMKM berbasis kuliner khas Cirebon dalam mengembangkan Halal tourism

\subsection{Manfaat Penelitian}

Manfaat yang akan diberikan pada penelitian ini ada dua yaitu manfaat secara teoritis dan manfaat praktis.

1) Manfaat Teoritis

Penelitian ini dapat menambah ilmu pengetahuan serta wawasan bagi penulis dan dapat memberikan kontribusi bagi pengembangan ilmu Ekonomi Islam khususnya penguatan UMKM guna mendorong Halal tourism menggunakan analisis SWOT dan AHP.

2) Manfaat Praktis

Penelitian ini diharapkan dapat bermanfaat untuk memberikan masukan bagi pemerintah dan pihak terkait untuk mengembangkan dan sebagai rekomendasi strategi untuk meningkatkan potensi pariHalal tourism di Cirebon melalui penelitian yang dilakukan. 


\section{BAB II \\ METODOLOGI PENELITIAN}

\subsection{Jenis dan Sumber Data}

Jenis dan sumber data yang digunakan dalam penelitian ini terdiri atas data primer dan sekunder. Data primer merupakan data yang diperoleh secara langsung melalui Focus Group Discussion (FGD) dan wawancara dari para narasumber yang terlibat dalam penelitian ini. Sedangkan data sekunder merupakan data yang tidak langsung yang diperoleh dari dokumen-dokumen. Dalam hal ini bersumber dari penelitian yang meliputi buku-buku bacaan yang berkaitan dengan judul penelitian dan data-data yang terkumpul.

\subsection{Teknik pengumpulan Data}

Adalah penelitian yang dilakukan pada perusahaan bersangkutan untuk memperoleh data yang berhubungan dengan penulisan dengan cara:

1. Wawancara, yaitu penelitian dengan mengadakan wawancara dan FGD secara langsung dengan beberapa stakeholders yang berkepentingan dengan penelitian ini.

2. Dokumentasi, yaitu penelitian yang dilakukan dengan jalan mengumpulkan dokumen-dokumen perusahaan yang berhubungan dengan penelitian ini

Narasumber yang terlibat dalam penelitian ini dipilih dengan menggunakan teknik purposive sampling. Artinya narasumber yang dipilih memiliki kriteria yang mewakili sejumlah besar kepentingan penguatan UMKM berbasis kuliner khas Cirebon. Jumlah narasumber yang terlibat berjumlah 10 orang antara lain:

Tabel 2.1 Narasumber yang Terlibat dalam Penelitian

\begin{tabular}{cllc}
\hline No. & \multicolumn{1}{c}{ Instansi } & Jabatan & Jumlah \\
\hline 1 & Dinas UMKM Kab. Cirebon & Kepala Dinas & 1 \\
2 & Dinas UMKM Kota Cirebon & Kepala Dinas & 1 \\
3 & Dinas Pariwisata Kab. Cirebon & Kepala Dinas & 1 \\
4 & Dinas Pariwisata Kota Cirebon & Kepala Dinas & 1 \\
5 & Perhimpunan UMKM Kabupaten Cirebon & Ketua & 1 \\
6 & Perhimpunan UMKM Kota Cirebon & Ketua & 1 \\
\hline
\end{tabular}


7 Perwakilan UMKM Kota dan Kabupaten

Pemilik

4

Cirebon

Usaha/Produsen

Total 10

\subsection{Analisis Data}

Alat analisis yang digunakan dalam penelitian ini terdiri atas (1) analisis SWOT, untuk menentukan faktor internal dan eksternal penguatan UMKM kuliner khas Cirebon. (2) Analytical Hiearchy Proccess (AHP) untuk menentukan prioritas strategi penguatan UMKM kuliner khas Cirebon menuju Cirebon Halal Tourism.

\subsubsection{Analisis SWOT}

Analisis SWOT (Strengths, Weakness, Opportunities, Threats) adalah singkatan dari lingkungan Internal Strengths dan Weaknesses sertalingkungan EksternalOpportunities dan Threats yang dihadapi UMKM. Analisis SWOT membandingkan antara faktor eksternal Peluang (Opportunities) dan Ancaman (Threats) dengan faktor internal Kekuatan (Strengths), dan Kelemahan (Weaknesses). (Rangkuti, 2013. hal. 20).Berikut ini merupakan penjelasan dari SWOT:

Tahapan dalam analisis SWOT yaitu

a. Matrik faktor strategi internal dan eksternal

b. Matriks profil kompetitif

c. Menyusun strategi SWOT

\subsubsection{Analytical Hierarchy Process (AHP)}

Analytical Hierarchy Process (AHP) digunakan untuk menetukan alternatif strategi sesuai dengan faktor penentu, aktor dan tujuan yang ingin dicapai dalam pengembangan konsumsi pangan di Kota dan Kabupaten Cirebon. Penentuan faktor, aktor dan tujuan dilakukan melalui kuesioner, sedangkan alternatif strategi dilakukan dengan analisis SWOT. Berikut ini adalah langkah-langkah dalam metode AHP (Saaty, 1991):

1. Mendefinisikan masalah dan menentukan solusi yang diinginkan;

2. Membuat struktur hirarki yang diawali dengan tujuan umum, dilanjutkan dengan subtujuan-subtujuan, kriteria dan kemungkinan alternatif pada tingkatan kriteria yang paling bawah;

3. Membuat matriks perbandingan berpasangan yang menggambarkan kontribusi relatif atau pengaruh setiap elemen terhadap masingmasing tujuan atau kriteria yang setingkat di atasnya. Perbandingan dilakukan berdasarkan judgement dari pengambil keputusan dengan menilai tingkat kepentingan suatu elemen dibandingkan elemen lainnya;

4. Melakukan perbandingan berpasangan, dimulaidari level hierarki paling atas yang ditujukan untuk memilih kriteria, misalnya $\mathrm{X}$, 
kemudian diambil elemen yang akan dibandingkan, missal X1, X2, dan X3. Sehingga, susunan elemen-elemen yang dibandingkan tersebut. Penentuan nilai kepentingan relative antar elemen menggunakan skala bilangan 1 sampai 9.Apabila suatu elemen dibandingkan dengan dirinya sendiri maka diberi nilai 1 . Jika elemen $\mathrm{i}$ dibandingkan dengan elemen $\mathrm{j}$ mendapatkan nilai tertentu, maka elemen $\mathrm{j}$ dibandingkan dengan elemen i merupakan kebalikannya;

5. Menghitung nilai eigen dan menguji konsistensinya, jika tidak konsisten pengambilan data diulangi;

6. Mengulangi langkah 3,4, dan 5 untuk seluruh tingkat hirarki;

7. Menghitung vektor eigen dari setiap matriks perbandingan berpasangan. Nilai vektor eigen merupakan bobot setiap elemen. Langkah ini untuk mensintesis judgement dalam penentuan prioritas elemen-elemen pada tingkat hirarki terendah sampai pencapaian tujuan;

8. Memeriksa konsistensi hierarki, jika nilainya kurang dari 10persen maka penilaian judgementditerima;

9. Memeriksa konsistensi hirarki. Jika nilainya lebih dari 10 persen maka penilaian data judgement harus diperbaiki.

\section{BAB III HASIL DAN PEMBAHASAN}

\subsection{Hasil Analisis SWOT}

Tahapan pengumpulan data primer merupakan suatu kegiatan pengklasifikasian dan pra analisis yang kemudian akan diperoleh faktafakta terkait UMKM berbasis kuliner khas daerah Cirebon.Fakta-fakta yang diperoleh kemudian diklasifikasikan ke dalam tabel IFE (Internal Factors Evaluation) dan EFE (Eksternal Factors Evaluation) serta setiap komponennya dianalisis

\subsubsection{Matriks IFE (Internal Factor Evaluation)}

Evaluasi Faktor Internal (Internal Factor Evaluation) merupakan identifikasi faktor-faktor lingkungan internal perusahaan dan menggolongkannya menjadi kekuatan (strenghts) dan kelemahan (weakness) yang berpengaruh terhadap UMKM berbasis kuliner khas daerah Cirebon.

Tabel 3.1 Matriks IFE

\begin{tabular}{ccccc}
\hline No. & Faktor-faktor Internal & Bobot & Rating & Skor \\
\hline 1. & a Kuliner yang telah lama dikenal & $\mathbf{0 . 1 2 7}$ & $\mathbf{1}$ & $\mathbf{0 . 1 2 7}$ \\
\hline
\end{tabular}




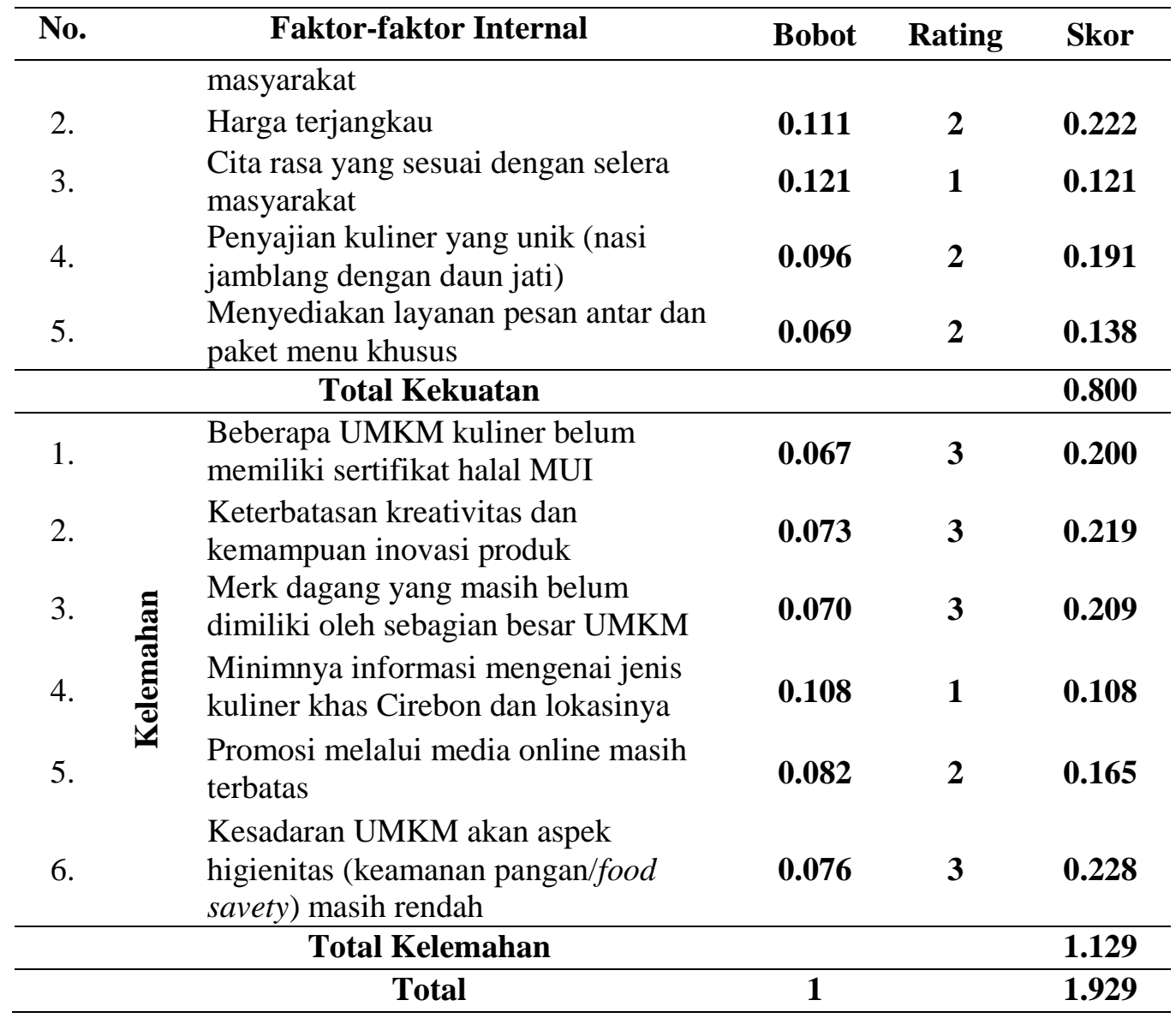

Sumber : Data primer diolah (2017)

\subsubsection{Matrik EFE(Eksternal Factor Evaluation)}

Evaluasi Faktor eksternal (Internal Factor Evaluation) merupakan identifikasi faktor-faktor lingkungan eksternal perusahaan dan menggolongkannya menjadi Peluang (opportunity) dan Ancaman (treath) yang berpengaruh terhadap penguatan UMKM berbasis kuliner khas Daerah Cirebon.

\section{Tabel 3.2 Hasil EFE}

\begin{tabular}{|c|c|c|c|c|c|}
\hline No. & & Faktor-faktor Eksternal & Bobot & Rating & Skor \\
\hline 1 & \multirow{3}{*}{ 巳一 } & $\begin{array}{l}\text { Cirebon sebagai kota wali, kota } \\
\text { budaya dan kota wisata religi }\end{array}$ & 0.123 & 4 & 0.494 \\
\hline 2 & & $\begin{array}{l}\text { Jumlah kunjungan wisatawan ke } \\
\text { Cirebon yang semakin meningkat }\end{array}$ & 0.123 & 4 & 0.494 \\
\hline 3 & & Akses transportasi yang lengkap & 0.113 & 4 & 0.453 \\
\hline
\end{tabular}




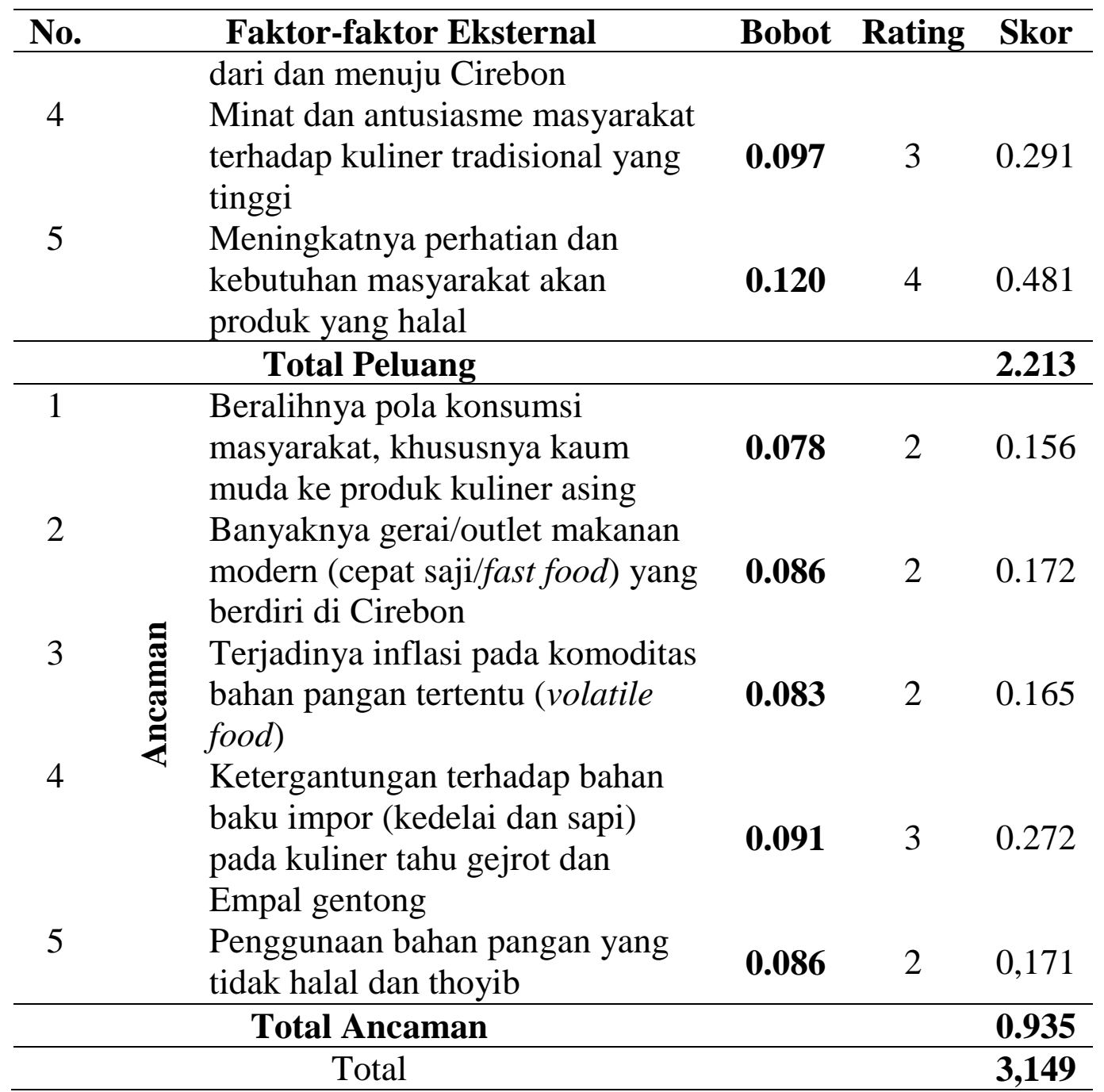

Sumber : Data primer diolah (2017)

\subsubsection{Matriks IE}

Matriks Internal Eksternal (IE) digunakan untuk mempermudah dalam memberikan pemilihan alternatif strategi. Informasi spesifik tentang lingkungan internal maupun eksternal perusahaan mengacu pada satu cara untuk mendapatkan suatu kemampuan strategi antara peluang eksternal dan kekuatan internal. Matriks IE diperoleh dari penggabungan hasil analisis faktor internal (IFE) dan eksternal (EFE)UMKM kuliner khas daerah Cirebon. Matriks internal dan eksternal disajikan dalam Gambar 3.1 berikut ini: 
IFE 1.929

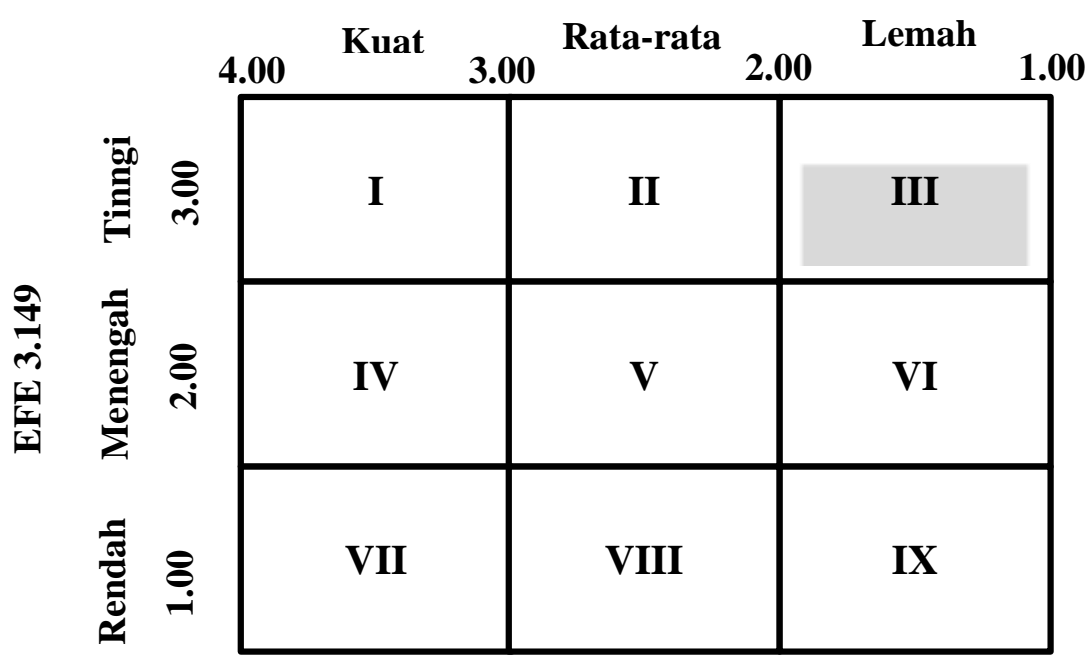

Gambar 3.1 Matriks Internal Eksternal

Sumber : data primer yang diolah (2017)

Dari hasil analisis matriks IE maka akan diketahui posisi UMKM kuliner khas daerah Cirebon saat ini. Hasil skor dari Matriks IFE sebesar 1,929 dan perolehan skor Matriks EFE sebesar 3,149, sehingga apabila masing-masing skor dipetakan kedalam Matriks IE maka posisi UMKM kuliner khas daerah Cirebon berada pada kuadran III dan lebih terperinci disajikan pada Gambar 3.2dibawah ini.

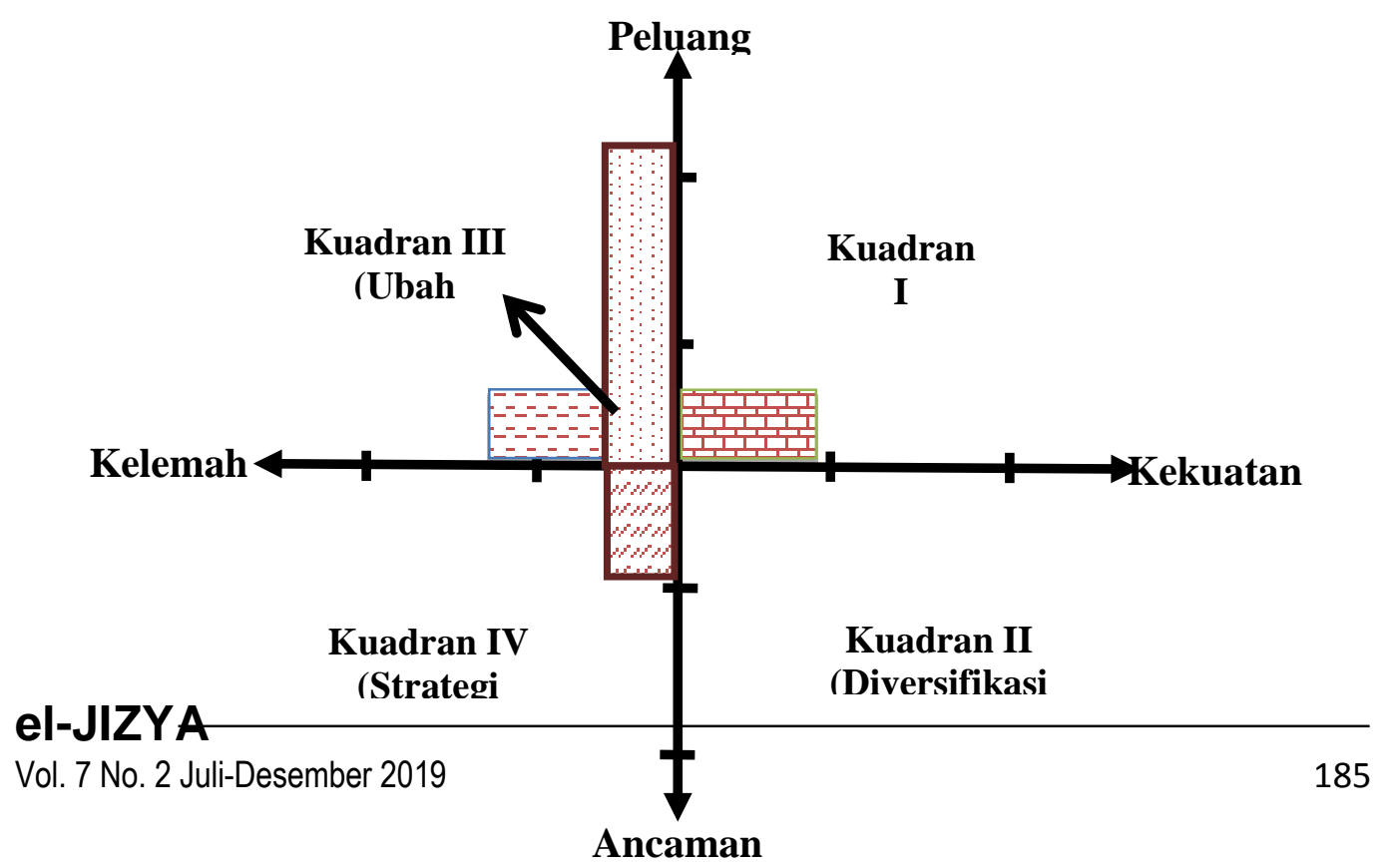




\section{Gambar 3.2Kuadran SWOT UMKM Kuliner Khas Cirebon}

Sumber : data primer yang diolah

Kuadran III UMKM kuliner khas Cirebon memiliki makna bahwa posisi ini menandakan sebuah organisasi yang lemah namun sangat berpeluang.Rekomendasi strategi yang diberikan adalah Ubah Strategi, artinya organisasi disarankan untuk mengubah strategi sebelumnya.Sebab, strategi yang lama dikhawatirkan sulit untuk dapat menangkap peluang yang ada sekaligus memperbaiki kinerja organisasi.

\subsubsection{Matriks Strategi SWOT}

Berdasarkan kuadran SWOT diatas, diperlukan strategi yang tepat untuk mengatasi kelemahan dengan memanfaatkan peluang yang ada.Strategi yang dipilih untuk permasalahan tersebut adalah Divestment/Investment. Strategi ini merupakan interaksi antara kelemahan organisasi dan peluang dari luar.Situasi seperti ini memberikan suatu pilihan pada situasi yang kabur.Peluang yang tersedia sangat meyakinkan namun tidak dapat dimanfaatkan karena kekuatan yang ada tidak cukup untuk menggarapnya. Pilihan keputusan yang diambil adalah (melepas peluang yang ada untuk dimanfaatkan organisasi lain) atau memaksakan menggarap peluang itu (investasi). Berikut disajikan Tabel 3.3tentang Matriks Strategi SWOT.

Tabel 3.3 Matriks Strategi SWOT

\begin{tabular}{|l|c|c|}
\hline & Faktor Peluang & Faktor Ancaman \\
\hline
\end{tabular}




\begin{tabular}{|c|c|c|}
\hline $\begin{array}{l}\text { Faktor } \\
\text { Eksternal }\end{array}$ & $\begin{array}{l}\text { 1. Cirebon sebagai kota } \\
\text { wali, kota budaya dan } \\
\text { kota wisata religi } \\
\text { 2. Jumlah kunjungan } \\
\text { wisatawan ke Cirebon } \\
\text { yang semakin } \\
\text { meningkat } \\
\text { 3. Akses transportasi } \\
\text { yang lengkap dari dan } \\
\text { menuju Cirebon } \\
\text { 4. Minat dan antusiasme } \\
\text { masyarakat terhadap } \\
\text { kuliner tradisional } \\
\text { yang tinggi } \\
\text { 5. Meningkatnya } \\
\text { perhatian dan } \\
\text { kebutuhan masyarakat } \\
\text { akan produk yang } \\
\text { halal }\end{array}$ & $\begin{array}{l}\text { 1. Beralihnya pola } \\
\text { konsumsi masyarakat, } \\
\text { khususnya kaum muda } \\
\text { ke produk kuliner asing } \\
\text { 2. Banyaknya gerai/outlet } \\
\text { makanan modern (cepat } \\
\text { saji/fast food) yang } \\
\text { berdiri di Cirebon } \\
\text { 3. Terjadinya inflasi pada } \\
\text { komoditas bahan } \\
\text { pangan tertentu } \\
\text { (volatile food) } \\
\text { 4. Ketergantungan } \\
\text { terhadap bahan baku } \\
\text { impor (kedelai dan } \\
\text { sapi) pada kuliner tahu } \\
\text { gejrot dan Empal } \\
\text { gentong } \\
\text { 5. Penggunaan bahan } \\
\text { pangan yang tidak halal } \\
\text { dan thoyib }\end{array}$ \\
\hline Faktor Kekuatan & $\begin{array}{c}\text { SO atau (Comparative } \\
\text { Advantage) }\end{array}$ & ST atau (Mobilization) \\
\hline 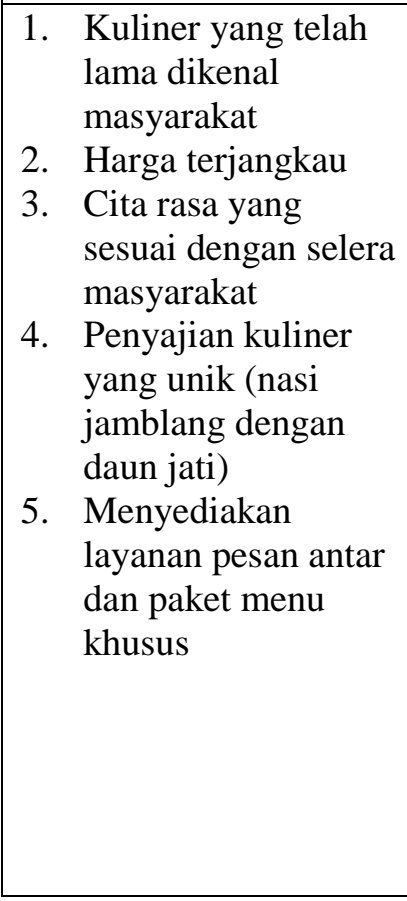 & 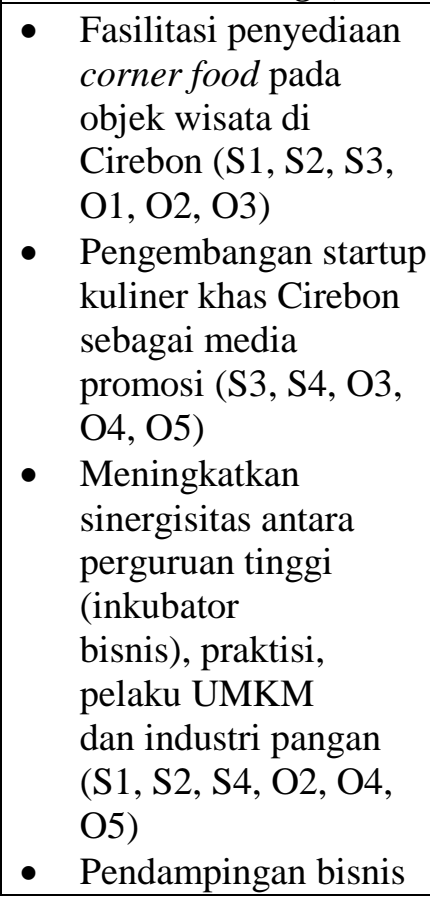 & $\begin{array}{l}\text { Meningkatkan kerja } \\
\text { sama } \\
\text { untuk menjaga } \\
\text { kontinuitas } \\
\text { ketersediaan bahan } \\
\text { baku antar } \\
\text { daerah (S1, S3, T3, T4, } \\
\text { T5) } \\
\text { - Membuat peraturan } \\
\text { daerah (perda) terkait } \\
\text { dengan pembatasan } \\
\text { pendirian gerai kuliner } \\
\text { asing di Cirebon (S1, } \\
\text { S2, S3, T1, T2) } \\
\text { - Promosi yang intensif } \\
\text { di kalangan kaum muda } \\
\text { melalui media online } \\
\text { (S3, S4, T1, T2) }\end{array}$ \\
\hline
\end{tabular}




\begin{tabular}{|c|c|c|}
\hline & $\begin{array}{l}\text { dan } \\
\text { meningkatnya } \\
\text { penyatuan } \\
\text { rantai industri }(\mathrm{S} 1, \mathrm{~S} 3 \text {, } \\
\mathrm{O} 4, \mathrm{O} 2, \mathrm{O} 3, \mathrm{O} 4)\end{array}$ & $\begin{array}{l}\text { Penyediaan } \\
\text { infrastruktur dan } \\
\text { jaringan pendukung } \\
\text { bagi melalui } \\
\text { penyediaan tempat } \\
\text { strategi bagi UMKM } \\
\text { kuliner khas Cirebon } \\
\text { (S2, S3, T1, T2) }\end{array}$ \\
\hline Faktor Kelemahan & $\begin{array}{c}\text { WO atau } \\
\text { (Divestment/Investment) }\end{array}$ & $\begin{array}{c}\text { WT atau (Damage } \\
\text { Control) }\end{array}$ \\
\hline 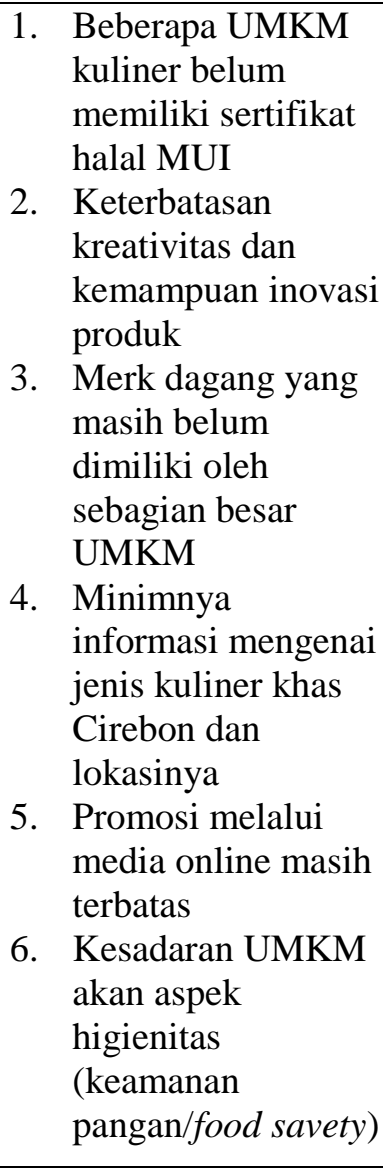 & $\begin{array}{l}\text { Menjaga kualitas } \\
\text { produk makanan dan } \\
\text { layanan konsumen } \\
\text { (W1, W2, W5, O2, } \\
\text { O4, O5) } \\
\text { Mengoptimalkan } \\
\text { kegiatan promosi } \\
\text { melalui iklan, media, } \\
\text { website (W2, W4, } \\
\text { W5, O2, O3, O4) } \\
\text { Mengoptimalkan } \\
\text { fungsi pemasaran } \\
\text { termasuk didalamnya } \\
\text { membangun merek } \\
\text { (branding), strategi } \\
\text { komunikasi, dan } \\
\text { penjualan (W2, W3, } \\
\text { W4, O2, O3, O4) } \\
\text { Pengembangan } \\
\text { destinasi yang terdiri } \\
\text { dari atraksi, } \\
\text { pembangunan } \\
\text { fasilitas, dan akses ke } \\
\text { lokasi yang } \\
\text { menunjang (W4, W5, } \\
\text { O1, O2, O3) }\end{array}$ & 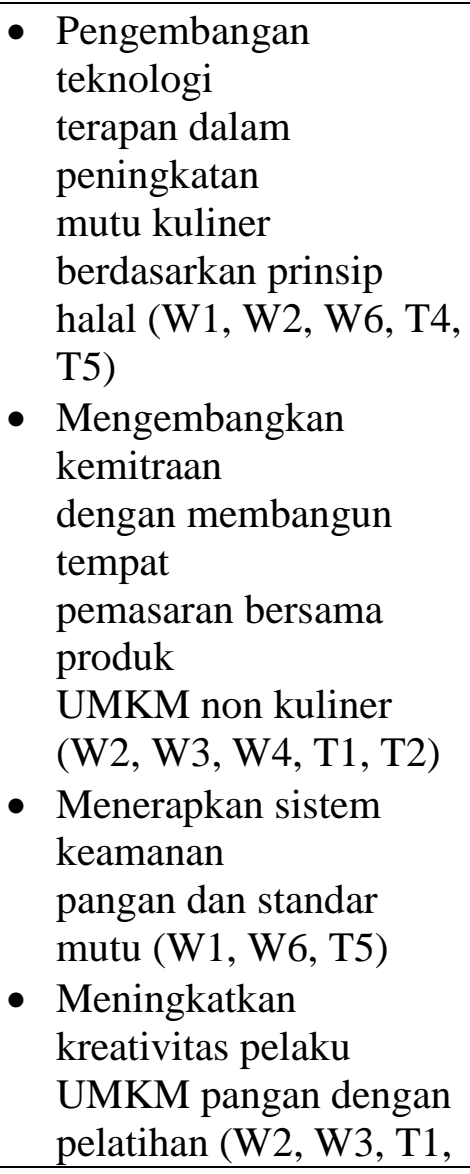 \\
\hline
\end{tabular}




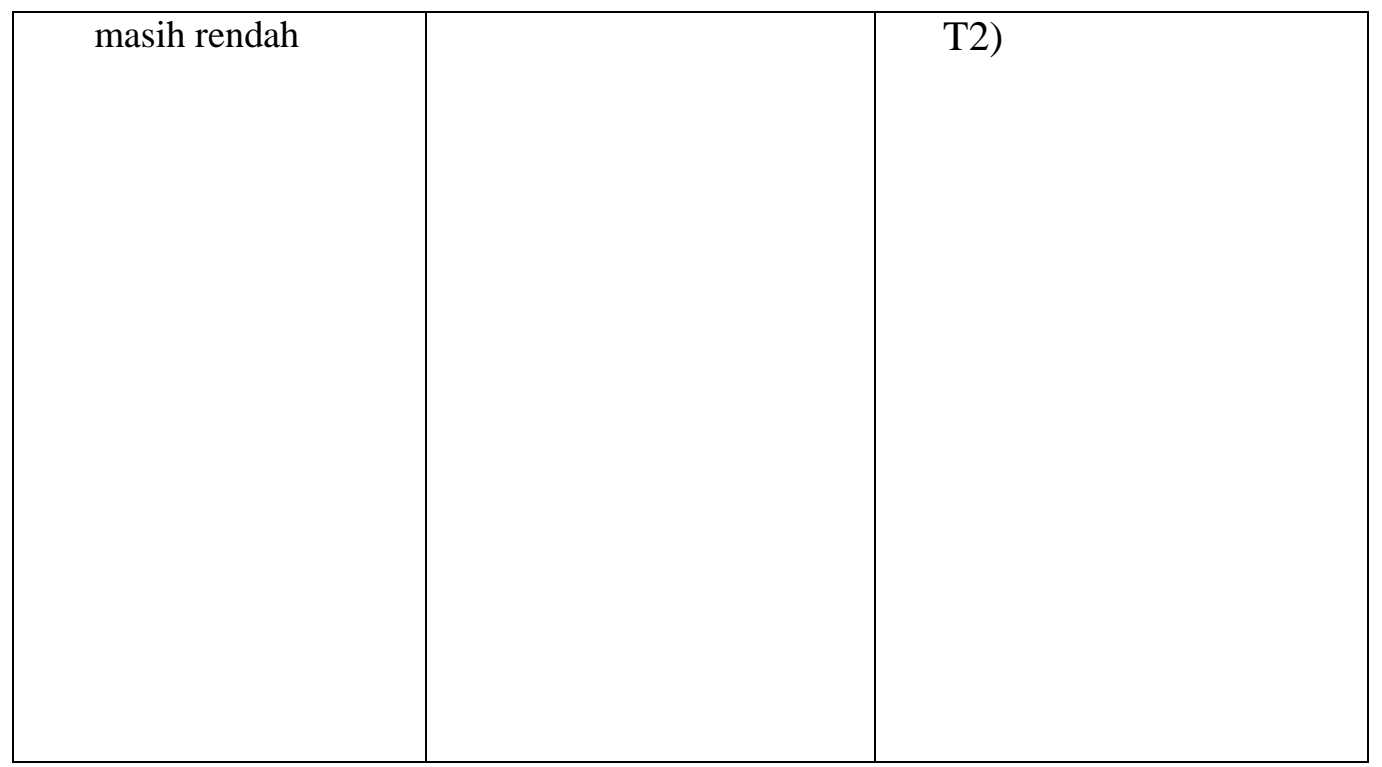

\subsection{Hasil Analisis AHP}

Berdasarkan hasil diskusi dengan narasumber terkait rancang bangun strategi pengembangan kuliner khas Cirebon, ditetapkan 3 (tiga) level yang mempengaruhi pengembangan kuliner yaitufaktor aspek penguatan (level 1), tujuan (level 2), dan strategi (level 3). Hasil pengolahan AHP menunjukkan hubungan antara elemen-elemendalam satu tingkat hierarki dengan elemen-elemen lainnya di tingkathierarki yang berbeda satu tingkatan diatasnya.Daripengolahan data, akan terlihat pengaruh antar suatu elemen ataufaktor pada satu tingkat terhadap sejumlah faktor lainnya pada tingkat hierarki dibawahnya.Hasil analisis AHP disajikan pada Gambar 3.3 


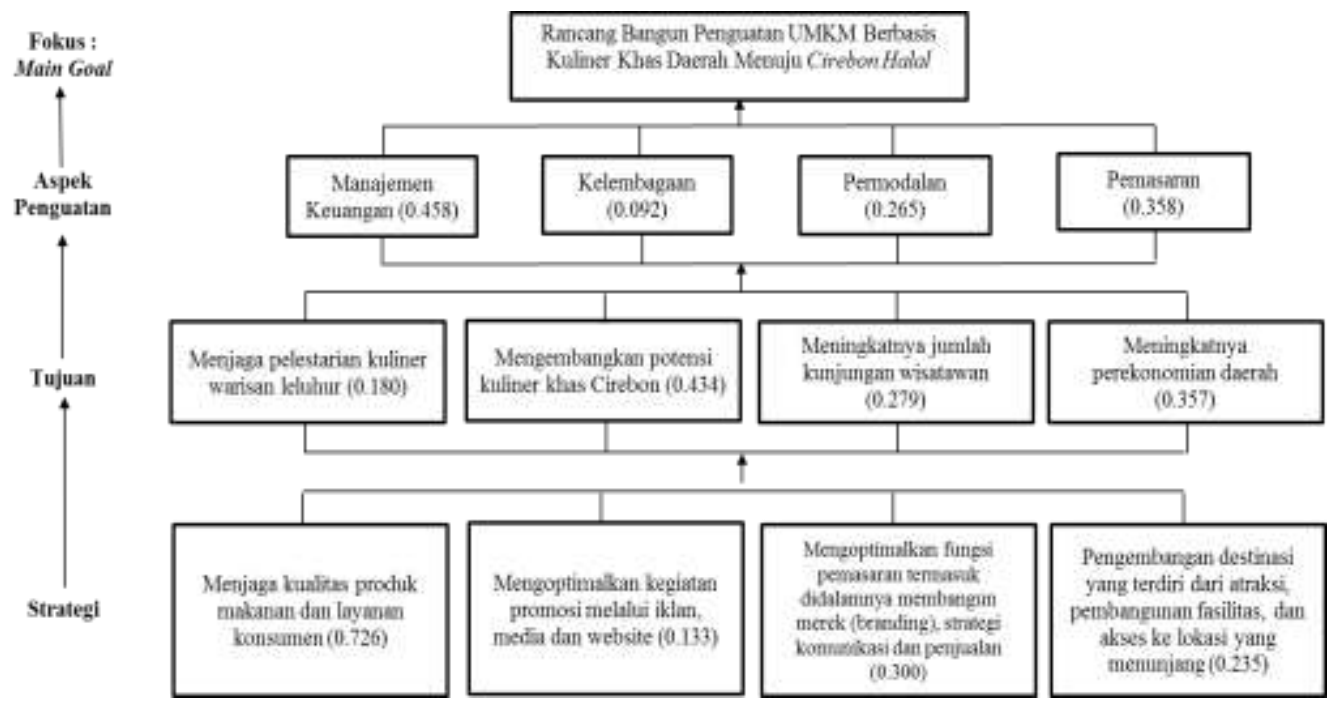

\section{Gambar 3.3 Hierarki Analisis AHP}

Sumber : data primer yang diolah

\subsubsection{Prioritas dan Pembobotan Pada Level Faktor Aspek Penguatan}

Pengolahan pada level faktor menunjukan tingkat pengaruh faktor terhadap fokus penguatan UMKM kuliner khas Cirebon. Hasil pengolahan pada level faktor aspek penguatan dapat dilihat pada Tabel 4.4.

\section{Tabel 3.4 Prioritas dan Bobot Level Faktor Aspek Penguatan}

\begin{tabular}{|c|c|c|}
\hline Elemen Faktor & Nilai Eigen Faktor & Prioritas \\
\hline Manajemen Keuangan & 0.458 & 1 \\
\hline Kelembagaan & 0.092 & 4 \\
\hline Permodalan & 0.265 & 3 \\
\hline Pemasaran & 0.358 & 2 \\
\hline
\end{tabular}

Sumber : data primer diolah (2017)

\subsubsection{Prioritas dan pembobotan pada Level Tujuan}

Berdasarkan hasil pengolahan kuesioner AHP, diperoleh hasil prioritas dan bobot dari masing-masing tujuan penguatan UMKM kuliner khas Cirebon. Hasil ini dapat dilihat pada Tabel 3.5.

\section{Tabel 3.5 Prioritas dan Bobot Level Tujuan}

\begin{tabular}{|c|c|c|}
\hline Elemen Faktor & Nilai Eigen Faktor & Prioritas \\
\hline Menjaga pelestarian kuliner warisan leluhur & 0.180 & 4 \\
\hline
\end{tabular}




\begin{tabular}{|l|l|l|}
\hline Mengembangkan potensi kuliner khas Cirebon & 0.430 & 1 \\
\hline Meningkatnya jumlah kunjungan wisatawan & 0.279 & 3 \\
\hline Meningkatnya perekonomian daerah & 0.357 & 2 \\
\hline
\end{tabular}

Sumber : data primer diolah (2017)

\subsubsection{Prioritas dan pembobotan pada Level Strategi}

Berdasarkan hasil pengolahan kuesioner AHP, diperoleh hasil prioritas dan bobot dari masing-masing strategi penguatan UMKM kuliner khas Cirebon. Hasil ini dapat dilihat pada Tabel 3.6.

Tabel 3.6 Prioritas dan Bobot Level Strategi

\begin{tabular}{|l|c|c|}
\hline \multicolumn{1}{|c|}{ Elemen Faktor } & Nilai Eigen Faktor & Prioritas \\
\hline $\begin{array}{l}\text { Menjaga kualitas produk makanan dan layanan } \\
\text { konsumen }\end{array}$ & 0.726 & 1 \\
\hline $\begin{array}{l}\text { Mengoptimalkan kegiatan promosi melalui iklan, } \\
\text { media dan website }\end{array}$ & 0.133 & 4 \\
\hline $\begin{array}{l}\text { Mengoptimalkan fungsi pemasaran termasuk } \\
\text { didalamnya membangun merek (branding), } \\
\text { strategi komunikasi, dan penjualan. }\end{array}$ & 0.300 & 2 \\
\hline $\begin{array}{l}\text { Pengembangan destinasi yang terdiri dari atraksi, } \\
\text { pembangunan fasilitas, dan akses ke lokasi yang } \\
\text { menunjang. }\end{array}$ & 0.235 & 3 \\
\hline
\end{tabular}

Sumber : data primer diolah (2017)

\section{BAB IV \\ KESIMPULAN DAN SARAN}

\subsection{Kesimpulan}

a. Identifikasi dari hasil penelitian diperoleh UMKM kuliner khas Cirebon adalah sebuah organisasi yang lemah namun sangat berpeluang.Rekomendasi strategi yang diberikan adalah Ubah Strategi.Strategi yang dipilih untuk permasalahan tersebut adalah Divestment/Investment.Strategi ini merupakan interaksi antara kelemahan organisasi dan peluang dari luar. Pilihan keputusan yang diambil adalah (melepas peluang yang ada untuk dimanfaatkan organisasi lain) atau memaksakan menggarap peluang itu (investasi). Adapun strategi penguatan UMKM berbasis kuliner khas Cirebon dalam mengembangkan halal tourism adalah sebagai berikut :

$\checkmark$ Menjaga kualitas produk makanan dan layanan konsumen 
$\checkmark$ Mengoptimalkan kegiatan promosi melalui iklan, media, dan website

$\checkmark$ Mengoptimalkan fungsi pemasaran termasuk didalamnya membangun merek (branding), strategi komunikasi, dan penjualan

$\checkmark$ Pengembangan destinasi yang terdiri dari atraksi, pembangunan fasilitas, dan akses ke lokasi yang menunjang.

b. Dalam rangka fokus penguatan UMKM berbasis kuliner khas daerah Cirebon menuju Cirebon Halal Tourism, maka aspek penguatan manajemen keuangan menjadi prioritas utama dalam peningkatan usaha dengan tujuan mengembangkan potensi kuliner khas Cirebon, untuk menguatkan hal tersebut maka strategi prioritasnya adalah menjaga kualitas produk makanan dan layanan konsumen.

\subsection{Saran}

Berdasarkan hasil penelitian serta analisis yang telah dilakukan , maka penulis memberikan sedikit masukan dan saran, baik untuk dinas Usaha Mikro Kecil dan Menengah, Dinas Parisiwsata dan para pelaku Usaha Mikro Kecil dan Menengah.

\subsubsection{Dinas UMKM}

a) Mengadakan pelatihan, diklat dan training bagi para UMKM kuliner tentang kualitas dan mutu kuliner, pelayanan kepada konsumen, dan promosi produk kuliner melalui iklan, media dan website bahkan jual beli online yang sedang gencar saat ini.

b) Membantu UMKM kuliner khas daerah Cirebon memasarkan produknya dengan mengadakan Bazar atau Expo tahunan secara massal dan besar-besaran khusus kuliner khas daerah Cirebon.

c) Membantu para UMKM kuliner khas Cirebon untuk mendapatkan Label Halal dari Majelis Ulama Indonesia dan izin Pangan Industri Rumah Tangga (PIRT) dari Dinas Kesehatan.

\subsubsection{Dinas Pariwisata}

a) Menyediakan stand-stand khusus kuliner khas daerah Cirebon di tempat pariwisata yang strategis dan banyak dikunjungi wisatawan baik lokal maupun manca negara.

b) Memasukkan promosi kuliner khas Cirebon dalam paket pariwisata Cirebon baik untuk wisatawan domestik maupun wisatawan mancanegara.

\subsubsection{UMKM Kuliner Khas daerah Cirebon.}


a) Mampu untuk menjaga kualitas produk makanan dan layanan konsumen.

b) Mengoptimalkan kegiatan promosi melalui iklan, media dan website.

c) Mengoptimalkan fungsi pemasaran termasuk didalamnya membangun merek (branding), strategi komunikasi, dan penjualan

d) Mengembangkan destinasi yang terdiri dari atraksi, pembangunan fasilitas, dan akses ke lokasi yang menunjang.

\section{DAFTAR PUSTAKA}

Ahsana Mustika Ati. 2011. Pengelolaan Wisata Religi (Studi Kasus Makam Sultan Hadiwijaya Untuk Pengembangan Dakwah)

Ariqa Nurwilda Sugiarti. 2015. Strategi Pengembangan Pari Halal

Tourism Untuk Meningkatkan Kunjungan Wisatawan Muslim

Domestik dan Mancanegara di Kota Bandung

Boo, H. V. 2011. Service Environment of Restaurants: Findings from the youth customers. Journal of ASIAN Behavioural Studies, 1 (2), May

Chookaew, S., chanin, O., Charatarawat, J., Sriprasert, P., \& Nimpaya, S. (2015). Increasing Halal Tourism Potential at Andaman Gulf in. Journal of Economics, Business and Management

Dinas Kebudayaan, Pariwisata, Pemuda dan Olahraga Kabupaten Cirebon [2016]

Dinas Pemuda Olahraga Kebudayaan dan Pariwisata Kota Cirebon [2016]

Dyah Ivana Sari. 2010. Objek Wisaata Religi Makam Sunan Muria(Studi Kehidupan Sosial Dan Ekonomi Masyarakat Desa Colo, Kecamatan Dawe, Kabupaten Kudus

Favalli, S., Skov, T., dan Byrne, D.V. 2013. Sensory perception and understanding of food uniqueness: From the traditional to the novel. Food Research International 50 (13), pp. 176-188

Fulia Aji Gustaman. 2009. Pengembangan Wisata Religi Dan Pemberdayaan Masyarakat Bagi Peningkatan Kehidupan SosialEkonomi

Harjanto Suwardono. 2015. Potensi Pengembangan Pariwisata Perhotelan Di Kota Semarang (Kajian Dari Perspektif Syariah) 
Munirah L dan Ismail H. N. 2012. Muslim Tourists' Typologi in Malaysia: Perspectives and Challenges. Proceedings of the Tourism and Hospitality International Conference. Malaysia: Department of Urban and Regional Planning, Faculty of Built Environment

Peraturan Mentri Pariwisata dan Ekonomi Kreatif Republik Indonesia nomor 2 tahun 2014 tentang pedoman penyelenggara usaha hotel syariah

Rangkuti, Freddy. 2013. Analisis SWOT: Teknik Membedah Kasus Bisnis. Jakarta: Gramedia

Saaty TL. 1993. Pengambilan Keputusan Bagi Para Pemimpin: Proses Hirarki Analisis Untuk Pengambilan Keputusan Dalam Situasi Yang Kompleks. Setiono L, Penerjemah ; Peniawati K, Editor. Jakarta: PT. Gramedia

Siddhartha, K. 2013. Consumer perception on Organized Fast Food Retail Outlets towards brand image in Bhopal, IRC's.International

Journal of Multidisciplinary Research in Social and Management Sciences, 1 (2)

Sureerat Chookaew, Oraphan chanin, Jirapa Charatarawat, Pingpis Sriprasert, dan Sudarat Nimpaya. 2015. Increasing Halal Tourism

Potential at Andaman Gulf in Thailand for Muslim Country

Timang Setyorin. 2004. Kebijakan Pariwisata Dalam Rangka Meningkatkan Pendapatan Ekonomi Masyarakat Kabupaten Semarang

Undang-undang Republik Indonesia No.20 Tahun 2008 